\title{
Media Use and Sexual Behavior: A Study of Adolescents in Selected Secondary Schools in Ede, Osun State
}

\section{Lanre-Babalola FO}

Department of Behavioral studies, Redeemer's University. Ede. Osun State, Nigeria

“Corresponding author: Lanre-Babalola FO, Department of Behavioral studies, Redeemer's University. Ede. Osun State, Nigeria, E-mail: lanrebabalolaf@run.edu.ng

Received date: Oct 16, 2017; Accepted date: Dec 29, 2017; Published date: Jan 3, 2018

Copyright: (c) 2018 Lanre-Babalola FO. This is an open-access article distributed under the terms of the Creative Commons Attribution License, which permits unrestricted use, distribution, and reproduction in any medium, provided the original author and source are credited.

\begin{abstract}
Overtime, mass media's influence evolved gradually together with the technology that carried mass mediated message; the trend of which has ultimately projected at the turn of the 21st century. The procession of new technologies and scientific breakthroughs in recent times is, however, persistent and is recounting on many fronts such as the electronic media and other forms of media, which are major tools in the transmission of information and digital content. Reacting to media development during the First and Second World War, Valdimir opined that "media is a powerful instrument which may be used for good or for ill and that, in the absence of adequate control; the latter possibility is on the more likely". It follows that the influence of media on the sexual behaviors of adolescents has increased when compared to recent years when the access of such information was quite limited and restricted. Sexual content has been made easily accessible as a result of increase in mediums which can provide this sometimes uncensored information. Media is an all-inclusive term that refers to a collection of communicatory mediums used to store or transmit information or data. Media is usually intended to inform or influence a wide range of audiences. Communication channels through which news, entertainment, education, data, or promotional messages are disseminated are called media. These media includes every broadcasting and narrowcasting medium such as newspapers, magazines, TV, radio, billboards, direct mail, telephone, fax, and, more significantly, the internet. Adolescence is a phenomenon which is referred to as the transitional stage between childhood and adulthood. In some cultures, adolescence is termed as a child physically coming of age, and acknowledged as the readiness to assume the adult roles of reproduction, parenting, and work.
\end{abstract}

Keywords: Media; Sociology; Secondary schools

\section{Introduction}

Overtime, mass media's influence evolved gradually together with the technology that carried mass mediated message; the trend of which has ultimately projected at the turn of the 21 st century. The procession of new technologies and scientific breakthroughs in recent times is, however, persistent and is recounting on many fronts such as the electronic media and other forms of media, which are major tools in the transmission of information and digital content. Reacting to media development during the First and Second World War, Valdimir opined that "media is a powerful instrument which may be used for good or for ill and that, in the absence of adequate control; the latter possibility is on the more likely" [1]. It follows that the influence of media on the sexual behaviors of adolescents has increased when compared to recent years when the access of such information was quite limited and restricted. Sexual content has been made easily accessible as a result of increase in mediums which can provide this sometimes uncensored information.

Media is an all-inclusive term that refers to a collection of communicatory mediums used to store or transmit information or data. Media is usually intended to inform or influence a wide range of audiences. Communication channels through which news, entertainment, education, data, or promotional messages are disseminated are called media. These media includes every broadcasting and narrowcasting medium such as newspapers, magazines, TV, radio, billboards, direct mail, telephone, fax, and, more significantly, the internet. Adolescence is a phenomenon which is referred to as the transitional stage between childhood and adulthood. In some cultures, adolescence is termed as a child physically coming of age, and acknowledged as the readiness to assume the adult roles of reproduction, parenting, and work. But generally in the world today, adolescence has become a relatively long life stage and it is generally marked at the beginning by both biological changes (growth spurt and secondary sexual characteristics such as development of breasts in girls, nocturnal emissions or wet dreams in boys) and by social factors (increased independence from parents and increasing influence of peers [2].

Adolescent changes are further influenced by the ease of access to information via media channels such as the internet, mobile phones, and computer and satellite televisions. In recent times, sexuality is largely celebrated through these channels in various forms including; shows, movies, music videos, and even sports. In most cases, adolescents will tend to imitate the behaviors of their movie, music or sports icon accessible through various channels and forms of media. As such, their sexual behaviors become majorly influenced.

\section{Statement of the Problem}

It is apparent that overtime; communication technology is evolving rapidly and has its benefactors across all ages and cultures. It has been observed that youths especially adolescents spend more time with their television sets (watching movies), mobile phones, laptops, palmtops, all accessing the internet for variety of reasons. Basically, this communication channels have wholly taken over the place of interpersonal relationships thereby providing room for this communication 
Page 2 of 5

channels to be both mediums for both positive and negative information [3].

Negative information such as pornography accessible via media channels such as the internet has an adverse effect on how adolescents think, feel or act sexually [4,5]. Furthermore, sexuality is often used as a symbol to portray different messages aimed at catching the attention of the viewers, through forms which include; musical videos, television advertisements and romantic movies. The ease of access of this information through the readily available media channels (such as mobile phones, laptops) creates a major dilemma in adolescent sexual behavior. The electronic media which consists of many social networking sites such as Facebook, Twitter, WhatsApp, Instagram etc., is characteristic of an in-flock of sexual contents and materials. More worrisome is the fact that these communication trends will be on a rapid increase even as the world of technology improves. Although many schools have created strict rules that restricts the use of handheld technology during school hours; many adolescents are still able to connect during school hours as they please, causing distractions as well as having a negative impact on their sexual and overall behaviors.

Although studies have been carried out on the adolescent sexual behavior among adolescents, many adolescents continue to experiment with risky sexual behaviors at younger ages. Age at sexual debut has decreased drastically particularly in urban slums, a reality however is that adolescents in less or fairly urbanised areas also now have access to virtually all media resources their counterparts in urban areas have Most studies on adolescent sexual behavior are anchored on adolescents in urban area and there is insufficient data on adolescents' sexual behavior and the probable influence of media use on their sexual behavior in 'averagely' urbanised areas of Nigeria [6]. Hence, this study seeks to investigate the influence of electronic media content on adolescent sexual behavior using adolescents respondents randomly selected from four secondary schools in Ede, Osun State.

\section{Research Questions}

The following research questions will guide this research work:

- How often and why do adolescents in secondary school students in Ede assess the electronic media?

- How do adolescent secondary school students in Ede behave sexually?

- How does electronic media content influence sexual behavior in adolescent secondary school students in Ede?

- Is there a significant gender difference in adolescent sexual behavior?

\section{Research Objectives}

The general objective of this study is to explore the influence of Media use, sexual behavior and Reproductive health outcomes among adolescents. The specific objectives are to:

- To document frequency and interest of electronic media use among adolescents in selected secondary schools in Ede,

- To document the sexual behavior of adolescents in selected secondary schools in Ede,

- To investigate the influence of electronic media content on the sexual behavior of adolescents in secondary schools in Ede,

- To investigate the gender difference in sexual behavior of adolescents in selected secondary school students in Ede.

\section{Hypothesis}

To answer the objectives of the study, the following hypothesis were tested:

\section{Hypothesis 1}

$\mathrm{H1}$ : There is significant relationship between the use of electronic media and adolescent sexual behavior.

H0: There is no significant relationship between the use of electronic media and adolescent sexual behavior.

\section{Hypothesis 2}

H1: There is significant difference between gender and adolescent sexual behavior?

H0: There is no significant difference between gender and adolescent sexual behavior

\section{Hypothesis 3:}

$\mathrm{H} 1$ : There is a significant difference between gender and electronic media use.

H0: there is no significant difference between gender and electronic media use.

\section{Significance of the Study}

The result of this research will help the government to formulate and enforce policies on the restriction on the kind of media content that should be transmitted through this electronic media channels. The school administrators may gain from this study on better insight into ways to help improve student sexual behavior. This could be achieved through better policies put in place to help the students concentrate better in class which will reflect in their performance level, relationship with others

This research work will be significant to teachers since have a direct contact with the students and they are the best to monitor the student and help them improve when the students are the class. Furthermore: This study will help parents and soon to be parents to be able to understand better the effects of social media and the media in general on children; this would help them make better choices when deciding to allow children have access to various forms of media and also to monitor their children on the type of information the get from the internet. This research work is very significant for students as they are the direct victims of the media contents and are the participants under study. The result of the study will help the students have a better understanding of the effects of electronic media on their sexual behavior, and this could help guide their choices of what kind of information they get from this Electronic Media.

\section{Scope of the Study}

The study covered adolescents senior secondary section of some selected high schools in Ede, Osun state with the age range of students between the ages of 13 to 19 . 


\section{Brief Review of Literature}

Over the last decade the daily experience of adolescents has been transformed by developments in electronic media, including the computer, the Internet, and cell phones. Relative rarities only a generation ago, they are the daily tools of communication, information, and amusement for a majority of adolescents. Beyond access, content and capabilities have exploded. Even television, long a ubiquitous presence in American households, has seen content change and has grown dramatically [7].

Technology and adolescents seem destined for each other; both are young, fast paced, and ever changing. In previous generations teens readily embraced new technologies, such as record players, TVs, cassette players, computers, and VCRs, but the past two decades have witnessed a virtual explosion in new technology, including cell phones, iPods, MP-3s, DVDs, and PDAs (personal digital assistants). This new technology has been enthusiastically embraced by adolescents and has led to an expanded vocabulary, including instant messaging ("IMing"), blogging, and text messaging. New technology has many social and educational benefits, but caregivers and educators have expressed concern about the dangers young people can be exposed to through these technologies. It came in as a new medium with more power of attraction and seemingly more social. Hence children have access to a lot of information. They are exposed all the time to information meant for adults. They can also access information on drugs or sex in a medium inaccessible to many parents or teachers. This becomes a big problem. The fact that no Government or commercial entity owns the net that there are no rules or regulations that govern it.

The effects of the electronic media have also been seen in the early stages of the development of a child, for example, in children between the ages of 2-5 years [8].They also opined that excessive exposure to the media influences the way children behave. They also believe that action-packed movies have greatly impacted on the behavior of children Electronic media content so affects adolescents by possibly making them Sexual active. Online sexual solicitation of children and adolescents represents a serious threat to the safety and well-being of those who are approached. A recent study indicates that reports of unwanted online solicitation have declined in recent years, perhaps due to factors ranging from better privacy controls, more education, and better law enforcement [7].

Furthermore; electronic media contents, also influences adolescent Sexual Activity. astonishingly, and despite long-standing concerns over the influence of sexual media content on the behavior of adolescents, there is very little relevant research in this area according to a recent review by Escobar-Chavez [7,9]. Several analyses have found that disclosure to sexual content in television and videos was related to more positive attitudes towards pre-marital sex, and to being sexually active, but it was not clear if there was a causal connection [7].

\section{Theoretical Framework}

Several theoretical approaches address the potential effects of media portrayals on young audiences. For this chapter, discussion on theories based on observational learning and information processing emphasize lasting effects of exposure to media contents. Thus, the study also applies 'Cultivation Theory' in terms of effect (which can be small, gradual, indirect but cumulative and significant) through exposure (depending upon heavy and light viewership of cable television) and 'Social Learning Theory' which holds that viewers attend and learn from models which are attractive, powerful, rewarding and similar to themselves. They do not usually act immediately on what they learn from television. The cultivation theory examines the long term effects of television. It states that the more time people spend 'living' in the television world, the more likely they are to believe social reality portrayed on television, thereby it leaving the public with a misconception of what is true in the world.

Television has become major parts of our life, the time spent watching TV, is more than any other activity except sleep and occupational duties $[10,11]$. The quantity of time people use watching $\mathrm{TV}$ is quite high. On average, persons in the developed world watch about 21 hours per week, which translates into nine years in a regular life time [12]. An adult in America watches 3 to 4 hours of television per day $[10,11]$. Also children spend more time watching television than any other waking activity. Kids and young people (ages 2-17) view television about 19 hoursand 40 minutes per week [13].

\section{Methodology}

This research work is explorative; a structured questionnaire was used to measure and assess the length of time the average high school student spend accessing electronic media contents such as watching home videos, social networking website and applications, etc. It was also used to examine whether or not these activities are impacting on their sexual behavior, and how important the media is to them in comparison to investing more time to other activities. Data was collected at four different secondary schools in the south-western part of Nigeria, specifically in Ede, Osun state among students between the ages of 13 to 19 . The researcher considered the possibility of the students having access to devices which would enable them has access to these electronic media contents.

\section{Ethical consideration}

Students were informed not to write their names on the questionnaires, and that their responses are completely voluntary. All data were well protected and were destroyed after completion of data entry.

\section{Findings}

The study investigated some constructs of overt and covert behavior to assess participants' sexual behavior. A little more than half; 206 (53.0\%) participants reported not sexually active, 125 (32.1\%) respondents will not be turned on sexually by love scenes on movies or TV, while $179(46.0 \%)$ respondents say that they will be turned on sexually by love scenes on TV or movies but only a little, while $40(10.3 \%)$ respondents say that they will be turned on sexually by love scenes on movies or TV furthermore; $42(10.8 \%)$ respondents say that they will very much be turned on sexually by love scenes on movies or $\mathrm{TV}$, while $3(0.8 \%)$ respondents made no response as to if love scenes on movies or TV turns them on sexually. 246 (3.2\%) respondents say they will not be turned on sexually by websites that have sexual contents, while $82(21.1 \%)$ respondents say that they will be turned on a little sexually by websites that have sexual contents, while 25 (6.4\%) respondents say that they will be turned on a lot sexually by websites that have sexual contents. Furthermore; 33 (8.5\%) respondents say that they will be very much be turned on sexually by websites that have sexual contents, while, $3(0.8 \%)$ respondents made no response as to if they will be turned on sexually by websites that have sexual contents. In addition, 27 (6.9\%) respondents very often get sexually aroused by electronic media content, while $38(9.8 \%)$ respondents often get 
Page 4 of 5

sexually aroused by electronic media content, while 113(29.0\%) less often get sexually aroused by electronic media content, while 204 (52.4\%) respondents never get sexually aroused by electronic media content (Table 1).

\section{Hypothesis 1}

\section{Correlation test table}

The correlation test analysis of the relationship between access to electronic media content and sexual behavior shows that there is a significant relationship between the accesses of electronic media content and sexual behavior; $r=-381 \mathrm{p}>0.05$ indicating an inverse significant relationship between the access to electronic media content and sexual behavior which is negative. Thus; the hypothesis which states that there is a significant relationship between the access of electronic media content and sexual behavior is hereby accepted (Table 2).

\begin{tabular}{|l|l|l|l|}
\hline Value & N & R & P \\
\hline Sexual behavior & 221 & -0.381 & $<0.05$ \\
\cline { 1 - 2 } $\begin{array}{l}\text { How often do you access electronic } \\
\text { media content }\end{array}$ & 217 & & \\
\cline { 1 - 2 } Source: Researcher's Survey 2015 & & \\
\hline
\end{tabular}

Table 1: Correlation test showing relationship between access to electronic media content and sexual behavior.

\section{Hypotheses 2}

The t-test analysis on the gender difference in electronic media use and adolescent sexual behavior $(\mathrm{t}=3.49, \mathrm{df}=219, \mathrm{p}=0.001)$. Thus: the hypothesis which states that there is a significant gender difference in electronic media use and adolescent sexual behavior is hereby accepted (Table 2).

\begin{tabular}{|l|l|l|l|l|l|l|}
\hline Gender & N & Mean & S.D & Df & T & P \\
\hline Male & 137 & 76.07 & 18.5 & 219 & 3.49 & $>0.01$ \\
\hline Female & 84 & 68.85 & 5.3 & & & \\
\hline \multicolumn{7}{|l}{ Source: Researcher's Survey 2015 }
\end{tabular}

Table 2: Independent sample t-test; gender and adolescent sexual behavior.

\section{Hypotheses 3}

Table 3 depicts that the t-test analysis in the difference between gender and electronic media use shows that there is a great significant differences between gender and electronic media use. $(t=-5.787$, $\mathrm{df}=370, \mathrm{p}=0.000$ ). From the results, it shows that males (mean=1.65) use electronic media more than the females. Thus: the hypothesis which states that there is a significant gender difference in electronic media use and adolescent sexual behavior is hereby accepted.

\begin{tabular}{|l|l|l|l|l|l|l|}
\hline Gender & N & Mean & S.D & Df & T & P \\
\hline Male & 205 & 1.65 & .818 & 370 & -5.787 & $>0.05$ \\
\hline
\end{tabular}

\begin{tabular}{|l|l|l|l|l|l|l|}
\hline Female & 167 & 2.19 & .975 & & & \\
\hline
\end{tabular}

Table 3: Relationship between gender and electronic media use.

\section{Discussion of Findings}

Findings from the data collected and analyzed shows that 144 (37.0\%) participants access electronic media more than five times every day. Results also show that 269 (67.9) participants use the internet for several reasons including companionship, leisure, entertainment and sexual arousal. Also, 218 (56.0\%) participants in this study agree that electronic media content influences their sexual behavior while the remaining 151 (38.8\%) disagree. The first hypothesis in this study states that: there is a significant gender differences in adolescent sexual behavior. The results from the analysis using correlation technique, the hypothesis tested states that there is a significant gender difference in adolescent sexual behavior. The second hypothesis states that: there is a significant relationship between the use of electronic media and sexual behavior. From the results, the hypothesis tested states that there is a significant relationship between the use of electronic media use and sexual behavior.

Previous research has shown that adolescents' access of electronic media influences their sexual behavior $[11,12]$. This is very evident from this research work as analysis shows that averagely, adolescents' access electronic media at least ones a day. Furthermore, the type of electronic media devices they use also influences how frequent they access this electronic media contents including the type of information they get from this media channels. Also, from statistics, most adolescents have access to smart phone more than other electronic devices which have no barrier as to who can own such media devices irrespective of quality or grade of the electronic media device.

Furthermore; review from a previous study shows those electronic media content influences the sexual behaviors of adolescents which this study also agrees to. The media serves as a tool which share both negative and positive messages [13]. This leaves target audiences to choose the kind of information they want to view. Also; in more recent times, sexual contents is what sells irrespective of the message being share, the target audience, etc. This is in concord with the response of study respondents who agree that electronic media content affects them negatively. Finally, the study was able to find out influence the electronic media content has on adolescent sexual behavior.

\section{Conclusion}

A probable limitation of this study which is that participants may provide only socially acceptable responses due to the nature of this study, certain responses may have been inhibited. However, based on the findings from this study, this research concludes the following.

- Electronic media content has a significant influence on the sexual behaviors of adolescents.

- There is a significant difference between gender and adolescent sexual behavior

- There is a significant difference between gender and electronic media use. 
Citation: Lanre-Babalola FO (2018) Media Use and Sexual Behavior: A Study of Adolescents in Selected Secondary Schools in Ede, Osun State. Arts Social Sci J 9: 319. doi:10.4172/2151-6200.1000319

Page 5 of 5

\section{Recommendations}

- Restrictions on sexual content in electronic media should be placed.

- Parental Advisory on explicit media content should be adhered to. Parents should monitor their children and make them to understand better the effects of these electronic media contents on them which would help them make better choices when deciding to allow children have access to various forms of media.

- Teachers: the teachers have a direct contact with the students and they are the best to monitor the student and help them improve when the students are the class.

- The administrators: may gain from this study better insight into ways to help improve student sexual and academic behavior. This could be achieved through better policies put in place to help the students concentrate better in class which will reflect in their performance level.

- Students: An awareness forum should be created for students to have a better understanding of the effects of social media on their lives, and this could help guide their perception, attitude etc. of sexuality.

\section{References}

1. Lazerfiel P (1975) Communicating Ideas with Film, Video, and Multimedia. Illinios University press.
2. Lawrence S (1993) Adolescence. (3rdedn), McGraw hill

3. Glenn GS (2001) Media effects research: A basic overview.

4. Dietz WH (1990) You are what you eat-what you eat is what you are. J of Adolescent Health Care 11: 76-81.

5. Greenberg BS, Busselle RW (2004) Soap operas and sexual activity: A Decade Later. J Commun 46: 153-160.

6. Adedimeji AA, Omololu FO, Odutolu O (2007) HIV Risk Perception and Constraints to Protective Behaviour among Young Slum Dwellers in Ibadan, Nigeria. J Health Popul and Nutr 25: 146-157.

7. Brett VB, Pilar M (2009) Adolescents and Electronic Media. Media and Risky Behaviours 9: 119.

8. Mangwere A, Wadesango N, Kurebwa M (2017) Influence of the Electronic Media on the Behaviour of Children/Teenagers in Zimbabwe. J Commun 4: 101-109.

9. Escobar-Chaves MD (2008) Online Communication and Adolescent Relationships. 1/147. Spring 3.

10. Comstock G, Chaffee S, Kautzman N (1978) Television and human behaviour. New York: Columbian University Press.

11. Kubey R, Cskiszentmihalyi M (2002) Television addiction is no mere metaphor. Scientific American 286: 74-80.

12. Shrum LJ, Burroughs JE, Rindfleisch A (2005) Television's Cultivation of Material Values. J Consumer Res 32: 473-479.

13. Abelman R, Atkin D (2010) What children watch when they watch TV Putting theory into practice. J broadcasting electron media 44: 143-154. 